\section{Respiratory failure with diffuse patchy lung infiltrates: an unusual presentation of squamous cell carcinoma}

\author{
Marc Meysman, Danny F Schoors, \\ Hendrik Reynaert, Marc Noppen, \\ Erwin Pierré, Walter Vincken
}

\begin{abstract}
The case history is presented of a patient with squamous cell carcinoma of the lung with diffuse bilateral pulmonary shadowing mimicking bronchioloalveolar cell carcinoma which led to type I respiratory failure.
\end{abstract}

(Thorax 1994;49:1271-1272)

\section{Case history}

A 45 year old white man with an unremarkable medical history was admitted with progressive dyspnoea. He had been a heavy cigarette smoker (25 pack-years) but had stopped two years previously. During the three months before admission he developed anorexia, progressive dyspnoea and a dry cough, and lost $8 \mathrm{~kg}$ in weight. Two days before admission he became breathless at rest. A chest radiograph showed diffuse patchy infiltrates and he was admitted for investigation.

On examination he was thin and cyanosed, with moderate respiratory distress and a breathing frequency of 28 breaths per minute. Blood pressure was $100 / 70 \mathrm{~mm} \mathrm{Hg}$, heart rate $108 /$ min, temperature $37 \cdot 2^{\circ} \mathrm{C}$. No lymphadenopathy was found. Dry crackles were audible over both lung fields. The haematocrit was $49.3 \%$, and the white cell count was $12.3 \times 10^{\%} / 1$ with $87 \%$ neutrophils. The erythrocyte sedimentation rate was $29 \mathrm{~mm} /$ hour. Breathing room air, blood gas tensions were $\mathrm{PaO}_{2} 6 \cdot 2 \mathrm{kPa}$, $\mathrm{PaCO}_{2} 4.5 \mathrm{kPa}$, and $\mathrm{pH} 7 \cdot 45$.

A chest radiograph showed diffuse patchy opacities involving both lung fields, paratracheal lymphadenopathy, a moderate increase in heart diameter, and no evidence of pleural disease (fig 1).

Microbiological examination of sputum and blood were negative. Fibreoptic bronchoscopy revealed diffuse non-specific inflammatory changes of the mucosa which was most pronounced in the lower lobes. No endobronchial tumour was seen and no malignant cells were found in the bronchoalveolar lavage fluid, cultures of which failed to grow aerobic bacteria, viruses, fungi, or mycobacteria. Biopsy samples of the bronchial mucosa were not obtained because of respiratory distress.

Although an infectious aetiology could not be proven, the patient was initially treated with intravenous fluids, oxygen via nasal prongs, and ceftazidime, isoniazid, rifampicin, and ethambutol intravenously. On the second day after admission dyspnoea and hypoxaemia worsened, necessitating endotracheal intubation and mechanical ventilation. Haemodynamic monitoring revealed a pulmonary artery wedge pressure of $18 \mathrm{mmHg}$, cardiac output of $4.7 \mathrm{l} / \mathrm{min}$, and a systemic vascular resistance of 750 dyn s cm${ }^{-5}$. Despite an $\mathrm{FiO}_{2}$ of $100 \%$ and positive end expiratory pressure, severe hypoxaemia persisted and the patient died the next day.

At post mortem examination both lungs showed numerous white nodules, evenly distributed over all lobes. No haematogenous metastases were noted on haematoxylin and eosin staining. An orceine stain was not done. The heart was normal.

Histological examination of the lungs revealed extensive alveolar infiltration by a squamous cell carcinoma (fig 2). There were no histological changes indicating pneumonia or pulmonary infarction. Furthermore, hilar and paratracheal lymph nodes were invaded by the same tumour. Pulmonary oedema and hyaline membranes suggestive of adult respiratory distress syndrome were also present.

\section{Discussion}

Diffuse neoplastic pulmonary disease with a predominantly acinar pattern has been demonstrated in haematogenous metastases, lymphoma, and bronchioloalveolar cell carcinoma of the lung. Such multifocal con-

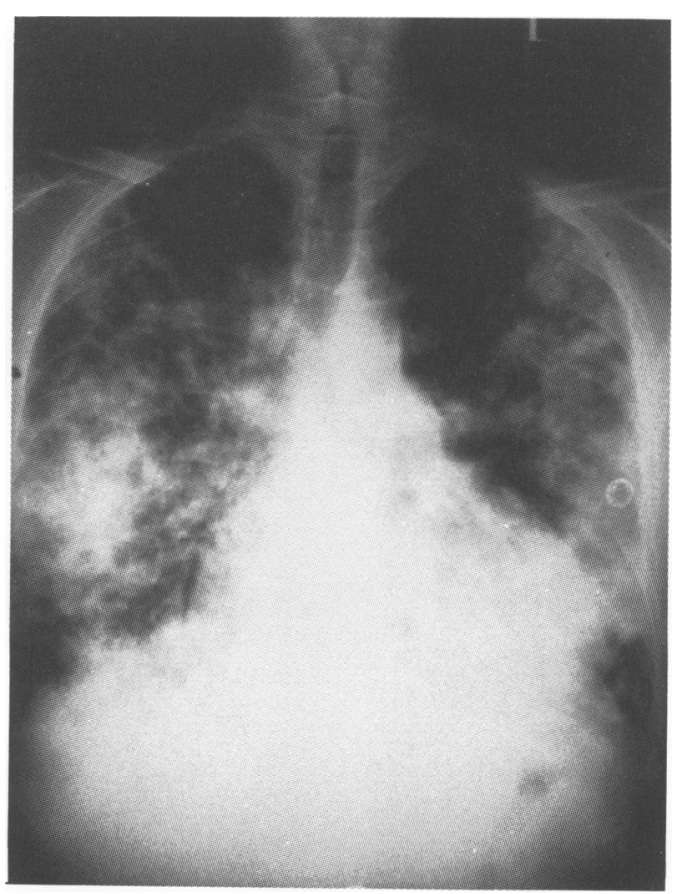

Figure 1 Chest radiograph obtained on admission revealing a diffuse patchy infiltrate throughout both lung fields, most noticeable in the right lower lobe. 


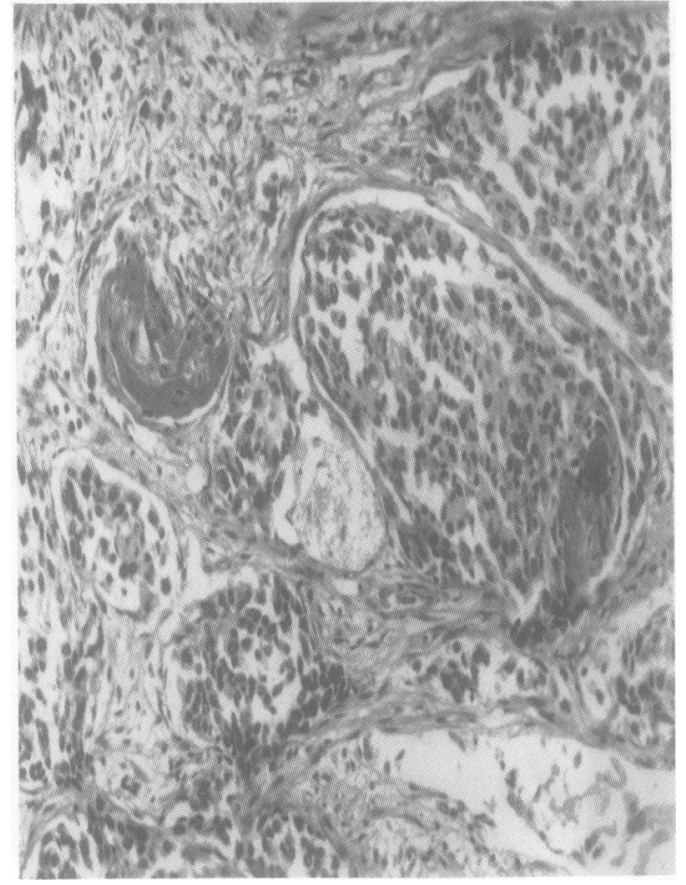

Figure 2 Post mortem lung tissue with squamous cell carcinoma infiltrating and obliterating the alveolar spaces. Stain: haematoxylin and eosin, original magnification $6 \times 19$ reduced to $69 \%$ in origination.

solidation is rarely found in squamous cell carcinoma of the lung, ${ }^{1}$ a tumour which accounts for $38-62 \%$ of primary lung tumours. ${ }^{2}$ Radiologically squamous cell carcinoma of the lung presents as atelectasis $(37 \%)$, a hilar or perihilar mass (35\%), or by obstructive pneumonitis or consolidation $(25 \%) .^{3}$ Analysis of the radiographic appearance of 263 cases of squamous cell carcinoma of the lung ${ }^{4}$ revealed only two cases of homogeneous opacification limited to one lobe or segment without decrease in volume. However, no clinical or pathological details of these two cases were given. Hind reported a case of lobar infiltration by a squamous cell carcinoma which closely resembled a bronchioloalveolar cell carcinoma. ${ }^{5}$

Bronchioloalveolar cell carcinoma has been described as "another great imitator", which in approximately two thirds of cases presents as a solitary peripheral lesion with sharp or fuzzy margins. ${ }^{6}$ It may also present as a multinodular lesion or a diffuse infiltrate, however, in which case the prognosis is considerably worse. Hilar and mediastinal adenopathy has been reported to occur in bronchioloalveolar cell carcinoma in $15-35 \%$ of cases. ${ }^{7}$

Although we are aware of the rarity of this presentation, we believe that squamous cell carcinoma of the lung should be added to the list of numerous causes of diffuse patchy infiltrates of the lung presenting with acute respiratory failure.

1 Fraser RG, Paré JAP, Paré PD, Fraser RS, Genereux GP. Diagnosis of diseases of the chest. 3rd edn. Philadelphia: WB Saunders, 1990:3084-5.

2 Spencer H. Carcinoma of the lung. Pathology of the lung. 3rd edn. Oxford: Pergamon Press, 1977:773-81.

3 Swett HA, Nagel JS, Sostman HD. Imaging methods in primary lung carcinoma. Clin Chest Med 1982;3:331-51.

4 Byrd RB, Miller WE, Carr DT, Payne WS, Woolner LB. The roentgenographic appearance of squamous cell carThe roentgenographic appearance of squamous cell car-
cinoma of the bronchus. Mayo Clin Proc 1968;43:327-32. cinoma of the bronchus. Mayo Clin Proc 1968;43:327-32.
Hind CRK. Lobar infiltration by squamous cell carcinoma. Thorax 1980;35:633-4.

6 Ludington LG, Verska JJ, Howard T, Kypridakis G, Brewer LA. Bronchiolar carcinoma (alveolar cell), another grea imitator: a review of 41 cases. Chest 1972;61:622-8.

7 Epstein DM. Bronchiolo-alveolar carcinoma. Semin Rontgenol 1990;25:105-11. 